\title{
Contrasting effects of hemiparasites on ecosystem processes: can positive litter effects offset the negative effects of parasitism?
}

\author{
Marko J. Spasojevic $\cdot$ Katharine N. Suding
}

Received: 12 May 2009 / Accepted: 8 July 2010 / Published online: 24 July 2010

(C) The Author(s) 2010. This article is published with open access at Springerlink.com

\begin{abstract}
Hemiparasites are known to influence community structure and ecosystem functioning, but the underlying mechanisms are not well studied. Variation in the impacts of hemiparasites on diversity and production could be due to the difference in the relative strength of two interacting pathways: direct negative effects of parasitism and positive effects on $\mathrm{N}$ availability via litter. Strong effects of parasitism should result in substantial changes in diversity and declines in productivity. Conversely, strong litter effects should result in minor changes in diversity and increased productivity. We conducted field-based surveys to determine the association of Castilleja occidentalis with diversity and productivity in the alpine tundra. To examine litter effects, we compared the decomposition of Castilleja litter with litter of four other abundant plant species, and examined the decomposition of those four species when mixed with Castilleja. Castilleja was associated with minor changes in diversity but almost a twofold increase in productivity and greater foliar $\mathrm{N}$ in co-occurring species. Our decomposition trials suggest litter effects are due to both the rapid $\mathrm{N}$ loss of Castilleja litter and the effects of mixing Castilleja litter with co-occurring species. Castilleja produces litter that accelerates decomposition in the alpine tundra, which could accelerate the slow $\mathrm{N}$ cycle and boost productivity. We speculate that these positive effects of litter outweigh the effects of parasitism in nutrient-poor systems with long-lived hemiparasites. Determining the
\end{abstract}

Communicated by Mercedes Bustamante.

M. J. Spasojevic $(\bowtie) \cdot$ K. N. Suding

Department of Ecology and Evolutionary Biology,

University of California-Irvine, 321 Steinhaus Hall,

Irvine, CA 92697-2525, USA

e-mail: mspasoje@uci.edu relative importance of parasitism and litter effects of this functional group is crucial to understand the strong but variable roles hemiparasites play in affecting community structure and ecosystem processes.

Keywords Nitrogen cycling · Decomposition - Alpine · Niwot Ridge

\section{Introduction}

While traditionally understudied (Pennings and Callaway 2002), hemiparasitic plants, parasitic plants that still photosynthesize, can play key roles in determining community structure and ecosystem function (Pennings and Callaway 1996; Davies et al. 1997; Marvier 1998; Quested et al. 2003a; Ameloot et al. 2005, Ameloot et al. 2008; Phoenix and Press 2005; Bardgett et al. 2006). However, the effects of hemiparasites are highly variable across species and systems (reviewed in Press and Phoenix 2005). Press (1998) proposed that the variation in effects of hemiparasites may be due to differences in the relative influence of parasitism and litter effects (Fig. 1). While several studies have examined the impacts of hemiparasites (i.e. Callaway and Pennings 1998; Quested et al. 2003b; Ameloot et al. 2005; Quested et al. 2005), there has been less attention to how parasitism and litter effects interact to impact community structure and ecosystem function (e.g. Bardgett et al. 2006).

Traditionally, it has been assumed that hemiparasites most substantially impact community structure and ecosystem function through parasitism (Press et al. 1999; Shen et al. 2006). Strong effects of parasitism have been often found, particularly for short-lived species in high-resource environments. For instance, in a meta-analysis of shortterm (1-2 years) sowing studies in grasslands, Ameloot 


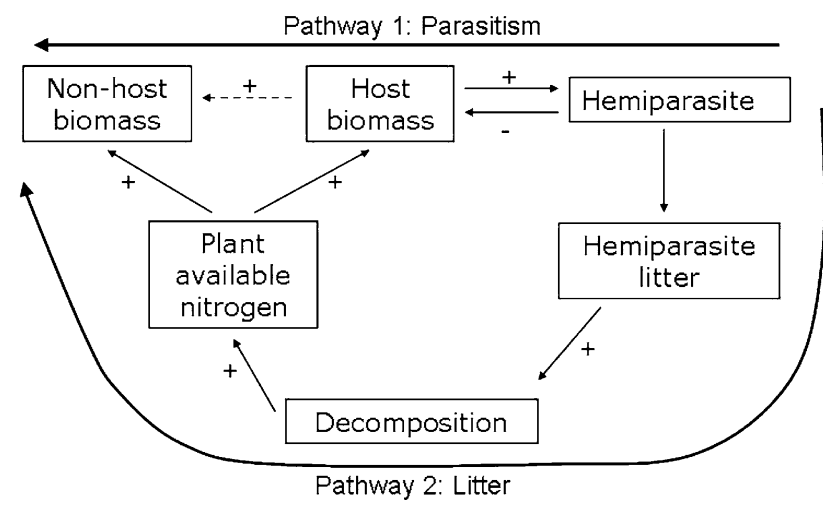

Fig. 1 The two interacting pathways by which hemiparasites can impact community structure and ecosystem function in an N-limited system (solid arrows represent direct effects and dashed arrows represent indirect effects). Pathway 1: parasitism can reduce host biomass. Reductions in host biomass are often greater than increases in hemiparasite growth, as hemiparasites often have low nutrient use efficiencies leading to reduced community productivity. The reduction in host plant biomass by the hemiparasite can increase community diversity by allowing the expansion of non-host subordinate species. Pathway 2: high-quality litter from hemiparasites can lead to accelerated decomposition. Thus, hemiparasites can make resources more readily available to the plant community in vicinity of the hemiparasite. Litter effects can increase primary productivity and reduce the effect of parasitism on diversity as competition for $\mathrm{N}$ would be reduced

et al. (2005) found that annual hemiparasitic Rhinanthus species reduce aboveground biomass of co-occurring species by an average of $40 \%$ and total community aboveground biomass (all species, including the parasite's biomass) by approximately $26 \%$. In these cases, the parasite biomass does not compensate for the biomass loss of the co-occurring species likely because hemiparasites often have low nutrient use efficiencies (Matthies 1995, 1997; Marvier 1998; Ameloot et al. 2005; Shen et al. 2006). Additionally, if the hemiparasite parasitizes particular host species, the species-specific reduction in biomass can change community diversity, either by allowing the expansion of the subordinate species (if a competitive dominant is parasitized) or further dominance (if the subordinants are parasitized) (Gibson and Watkinson 1992; Davies et al. 1997; Callaway and Pennings 1998; Marvier 1998; Hedberg et al. 2005; Westbury and Dunnett 2007). Thus, parasitism can be predicted to negatively affect productivity and also impact (either positively or negatively) diversity. We refer to these effects as the "parasitism pathway" (Fig. 1).

Hemiparasites can also affect ecosystem function through a second pathway: litter effects (Fig. 1). Hemiparasite litter often has concentrations of foliar nutrients higher than their hosts, typically being two- to fourfold greater for $\mathrm{N}$ and P (Quested et al. 2003a). Their litter has been found to decompose faster and release nutrients more rapidly than litter of co-occurring species and to stimulate the decomposition of more recalcitrant litters of co-occurring species
(Quested et al. 2002, 2005). Thus, hemiparasites can facilitate the release of nutrients, potentially making more resources available to co-occurring species in the vicinity of the hemiparasite (Quested et al. 2003a). If production is limited by these nutrients, litter effects via increased nutrient availability, could compensate for the decrease in community productivity due to direct parasitism effects, resulting in an increase in primary productivity (positive net effects). The impact on diversity would also diminish, as species-specific reduction in host biomass would be smaller. Additionally, longer lived hemiparasites have the potential for stronger litter effects as there is likely greater long-term litter accumulation. Thus, via the litter pathway, hemiparasites may have positive net effects on productivity and weaker impacts on diversity. Litter effects have been less studied, but we expect them to be most strong for longlived perennial hemiparasites in nutrient-poor systems (Press 1998; Quested 2008).

Given these two pathways, the effects of hemiparasites on productivity and diversity should depend on whether hemiparasites more strongly reduce host growth (parasitism) or enhance nutrient cycling (litter effects). Moreover, the relative strength of the parasitism and litter pathways may depend on the nutrient status of the system in which they are found or the life span of the hemiparasite. Here we focus on impacts of hemiparasitic Castilleja occidentalis [Orobanchaceae; nomenclature follows Weber and Wittmann (2001); all species referred to by genus hereafter] in dry meadow alpine tundra. As it is a perennial, non-rhizomatous, shallow-rooted hemiparasite (Weber and Wittmann 2001) in an N-limited system, we hypothesized that Castilleja will be associated with weak effects on community diversity and positive effects on biomass production due to strong positive litter effects on decomposition and nutrient cycling. We conducted field-based surveys to determine the association of Castilleja with community diversity and productivity. To test for litter effects, we conducted litter decomposition trials with Castilleja, four abundant species, and mixtures of species.

\section{Materials and methods}

This study was conducted on Niwot Ridge $\left(40^{\circ} 03^{\prime} \mathrm{N}\right.$, $105^{\circ} 35^{\prime} \mathrm{W}$ ) which is located in the Front Range of the Colorado Rocky Mountains. Niwot Ridge has a short growing season (approx 2-3 months) with a mean annual temperature of $-3^{\circ} \mathrm{C}\left(6.4^{\circ} \mathrm{C}\right.$ in the growing season) and an average annual precipitation of $930 \mathrm{~mm}$, with the majority of the precipitation (94\%) falling as snow (Greenland and Losleben 2001). Our study site was located at $3,550 \mathrm{~m}$ elevation in a saddle between two small knolls in the dry meadow tundra. Dry meadow tundra is characterized by relatively 
low nutrient and water availability with $\mathrm{N}$ limiting primary productivity (Bowman et al. 1993).

While Castilleja species are widespread and abundant (Chuang and Heckard 1991), their community and ecosystem effects have not been well studied. Castilleja occidentalis is a long-lived herbaceous hemiparasite distributed throughout the Rocky Mountain region of North America (Weber and Wittmann 2001). While we were not able to determine which species Castilleja was parasitizing from field observations, it is thought that most Castilleja species can parasitize a wide range of host species in this study (D. Tank, Personal Communication).

To determine the relationships of Castilleja abundance to diversity, aboveground production, and resource availability, fifteen $0.5-\mathrm{m}^{2}$ matched paired plots (30 plots total) were set up within a $50-\mathrm{m}^{2}$ area. For each pair, one plot had a higher abundance of Castilleja (+CAS plots), and a second plot had low to no Castilleja (-CAS plots). Paired plots were no more than $1.5 \mathrm{~m}$ apart; the exact distance depended on the surrounding vegetation and topography. Species presence and cover were estimated in each plot using the point-intercept method with 50 points. For each plot, richness, evenness, and Simpson's diversity index were calculated (excluding Castilleja from all calculations). Plot designations did not change between 2006 and 2007; no Castilleja individuals were seen in -CAS plots in 2007.

Aboveground biomass was measured in all 30 plots in early August 2006 and 2007 by clipping all current year's vascular plants to ground level in one $10-\mathrm{cm} \times 10-\mathrm{cm}$ subplot within each plot. Biomass was then dried for 4 days at $55^{\circ} \mathrm{C}$ and weighed to the nearest $0.01 \mathrm{~g}$. Then, to determine foliar $\mathrm{N}$ and $\mathrm{C}$, we ground and analyzed the plot biomass samples for $\mathrm{N}$ and $\mathrm{C}$ content via gas combustion (Siegel et al. 1982). In plots containing Castilleja, we assessed foliar $\mathrm{N}$ of Castilleja separately from the non-Castilleja biomass. In August 2007, belowground biomass was harvested by removing soil to a depth of $10 \mathrm{~cm}$ from the same $10-\mathrm{cm}^{2}$ subplot as the aboveground biomass harvest. Soil was sieved to remove all coarse roots and the remaining fine roots were extracted by water floatation to quantify belowground biomass. In August 2006, two 10-cm-deep soil cores were taken from the same location as each biomass harvest, bulked, and sieved. Soil extractable inorganic $\mathrm{N}$ was obtained from the bulked soil cores. Extracts of $2 \mathrm{M}$ $\mathrm{KCl}$ were analyzed colorimetrically for $\mathrm{NO}_{3}{ }^{-}$and $\mathrm{NH}_{4}{ }^{+}$ with a flow injection autoanalyzer (Lachat Instruments, Milwaukee, WI). For each bulked soil sample, gravimetric soil moisture was determined by placing $10 \mathrm{~g}$ of fieldcollected soil in aluminum tins and drying it at $80^{\circ} \mathrm{C}$ for 4 days to determine the dry soil mass.

To determine if Castilleja litter affects decomposition, leaf litter from Castilleja and four abundant species-Geum rossii (Rosaceae), Artemisia scopulorum (Asteraceae),
Carex scopulorum (Cyperaceae), and Kobresia myosuroides (Cyperaceae)—was collected from a $1-\mathrm{km}^{2}$ area of Niwot Ridge. Litter was air dried at room temperature for 1 week. We constructed 209 litter bags $(10 \mathrm{~cm} \times 20 \mathrm{~cm})$ from 1 -mm fiberglass mesh. Four grams of litter were placed in bags in the following treatments: each of the five species alone, a two species mix of Castilleja with each of the four non-hemiparasite species individually, a mix of the four non-hemiparasite species together (community mix) and a mix of all four non-hemiparasite species plus Castilleja (11 treatments total). Litter bags were placed on the soil surface in areas without existing hemiparasites or N-fixers on 08 September 2006, $1 \mathrm{~m}$ apart, with two bags of the same fill and collection date at each point. Litter bags were collected at 5 times: 8 September 2006, 13 June 2007, 15 September 2007, 13 June 2008, and 12 August 2008. The first collection, on 8 September 2006, was to quantify any loss of material from transport to and from the field. Litter bags collected on 8 September 2006 were replicated 3 times and the other four collection times were replicated 4 times. After collection, litter bags were returned to the lab, the remaining litter was weighed to determine mass loss, then ground and analyzed for $\mathrm{N}$ loss via gas combustion (Siegel et al. 1982). Observed mass loss was determined by subtracting the fill weight at each collection time from the initial fill mass, corrected for loss from transport (mass loss on the 8 September collection). Observed $\mathrm{N}$ loss was calculated as the difference between initial litter $\mathrm{N}$ (time zero; litter dry weight $\times \mathrm{N}$ concentration) and litter $\mathrm{N}$ for each time point.

\section{Statistical analyses}

To determine the relationship of Castilleja to all diversity measures (richness, evenness, and Simpson's diversity) and all measures of ecosystem function (inorganic soil $\mathrm{N}$, soil moisture, and biomass) we used a $t$ test with plot (+CAS or -CAS) as a categorical variable. Simpson's diversity and evenness were log transformed to meet the assumptions of normality. The relationship between biomass and soil moisture was tested using a linear regression. Individual species $\mathrm{C}: \mathrm{N}$, mass loss and $\mathrm{N}$ loss were compared at each time point using a one-way ANOVA. The observed mass and $\mathrm{N}$ losses were compared with expected values at each time point using a $t$ test assuming that mixtures of litter decompose the same as their components do alone for each treatment. The expected values for a mixture were calculated as $\left[\left(\right.\right.$ Species $\mathrm{A}_{\text {alone }}+$ Species $\left.\left.\mathrm{B}_{\text {alone }}\right) / 2\right]$ for a two species mixture. We calculated the annual decay constant $(k)$ using the single negative exponential model (Harmon et al. 1999) for both observed and expected mass loss for each replicate. Average $k$ for each treatment was then compared using a $t$ test. All statistics were preformed using JMP version 5.1. 


\section{Results}

Effects of Castilleja on community structure

At the community level, we found no significant difference in richness $\left(t_{1,28}=-0.69, P=0.49\right)$, evenness $\left(t_{1,28}=0.67\right.$, $P=0.57)$ or Simpson's diversity index $\left(t_{1,28}=0.90\right.$, $P=0.38$ ) between + CAS and - CAS plots. While we found no difference in species composition between +CAS and -CAS plots, we did find a small difference in species abundance: Geum had lower cover in association with Castilleja $\left(t_{1,28}=-2.16, P=0.04\right)$.

\section{Effects of Castilleja on ecosystem function}

In contrast to the minor impact on community structure, aboveground biomass was almost twofold greater in association with Castilleja $\left(+\mathrm{CAS}=449 \mathrm{~g} / \mathrm{m}^{2},-\right.$ CAS $283 \mathrm{~g} / \mathrm{m}^{2}$; $\left.t_{1,28}=4.45, P<0.001\right)$. The difference in aboveground biomass was due to the production of Castilleja; $36 \%$ of the biomass in the +CAS plots was Castilleja. Forb, grass, and $\mathrm{N}$-fixer biomass were all similar between +CAS and -CAS plots. Shrubs were relatively rare in the study site, but it did appear that Castilleja was associated with lower shrub biomass; shrub biomass was $8.4 \mathrm{~g} / \mathrm{m}^{2}$ (97\%) lower in the + CAS plots $\left(t_{1,28}=-2.00, P=0.05\right.$; Fig. 2$)$. Additionally, there was a trend toward greater belowground biomass in the +CAS plots $\left(+\mathrm{CAS}=1,341 \mathrm{~g} / \mathrm{m}^{2}, \quad-\right.$ CAS $904 \mathrm{~g} / \mathrm{m}^{2}$; $t_{1,28}=2.04, P=0.06$; Fig. 2). Soil moisture was $25 \%$ lower in association with Castilleja $\left(t_{1,28}=-2.34, P=0.03\right.$; Fig. 3a), but this difference in soil moisture was not correlated with total biomass in our plots $\left(r^{2}=0.02, F_{1,28}=1.62\right.$, $P=0.21)$. Extractable soil inorganic $\mathrm{N}$ did not differ between plots with Castilleja and the surrounding tundra $\left(\mathrm{NH}_{4}{ }^{+}, t_{1,28}=0.21, P=0.83 ; \mathrm{NO}_{3}{ }^{-}, t_{1,28}=0.36, P=0.72\right.$; Fig. 3b). Lastly, Castilleja had a higher foliar $\mathrm{N}$ content than all the other focal species $\left(F_{5,12}=56.31, P<0.0001\right)$ and foliar $\mathrm{N}$ of the non-Castilleja vegetation was higher in + CAS plots $\left(t_{1,28}=-2.37 P=0.04\right.$; Fig. $\left.3 \mathrm{c}\right)$.

Decomposition of Castilleja was generally faster than the co-occurring species. Mass loss and $k$ of Castilleja were greater than the graminoid species (Carex, Kobresia) and the community mix, but not for the other forb species (Geum and Artemisia; Fig. 4a; Table 1). N loss was significantly greater in Castilleja compared with all other species at all time points (Fig. 4b).

Litter inputs of Castilleja had a variety of effects on decomposition in mixtures. Mass loss rate was largely unaffected by the presence of Castilleja litter. The observed and expected $k$ was similar in all cases except the Carex + Castilleja and the Community + Castilleja mixes (Table 1), where the presence of Castilleja litter increased decay rates compared with expected values $\left(t_{1,6}=-2.32\right.$,

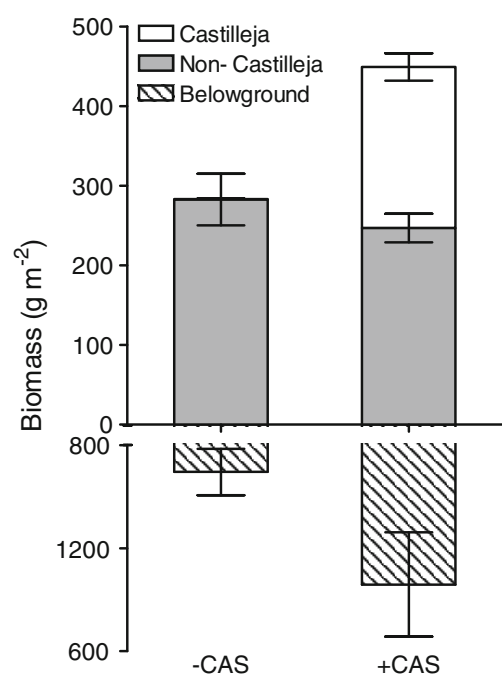

Fig. 2 Mean $( \pm$ SE) values of biomass in association with Castilleja $(+C A S)$ and the surrounding tundra $(-C A S)$. Aboveground biomass was almost twofold greater in +CAS than in -CAS. The difference in aboveground biomass was due primarily to the production of Castilleja (white bar); total biomass of the non-Castilleja portion of the community (gray bar) did not differ between the two communities. Forb, grass, and $\mathrm{N}$-fixer biomass were all similar between +CAS and -CAS plots; however, shrub biomass was lower in the +CAS plots. Furthermore, belowground biomass (indicated by negative numbers; hatched bar) was marginally greater in the +CAS plots as compared to -CAS plots. $y$-axis cut for viewing purposes. $n=15$ for each treatment

$P=0.06$, and $t_{1,6}=-2.79, P=0.03$, respectively). $\mathrm{N}$ loss was significantly slowed when Castilleja litter was mixed with the other forb species (Geum and Artemisia) and significantly accelerated when Castilleja litter was mixed with the graminoid species (Carex, Kobresia), although the effects varied over time (Fig. 5). Castilleja litter did not affect $\mathrm{N}$ loss from the community mixture except for a marginal acceleration of loss at the 644-day point.

\section{Discussion}

Our results support the idea that litter effects of longer lived hemiparasites in nutrient-poor systems may compensate for the negative effects of parasitism on the host community by increasing the amount of $\mathrm{N}$ available in the system. Castilleja was associated with increased productivity in the alpine tundra, a result consistent with other work on longlived hemiparasites in nutrient-poor systems. March and Watson (2007) found that understory plant biomass increased with increasing hemiparasitic mistletoe canopy biomass in eucalypt forests. Additionally, Quested et al. (2003b) found that subarctic seedlings grown in litter from hemiparasitic Bartsia had 50\% more biomass than seedlings grown with non-hemiparasite litter. While March and Watson (2007) and Quested et al. (2003b) both found that 

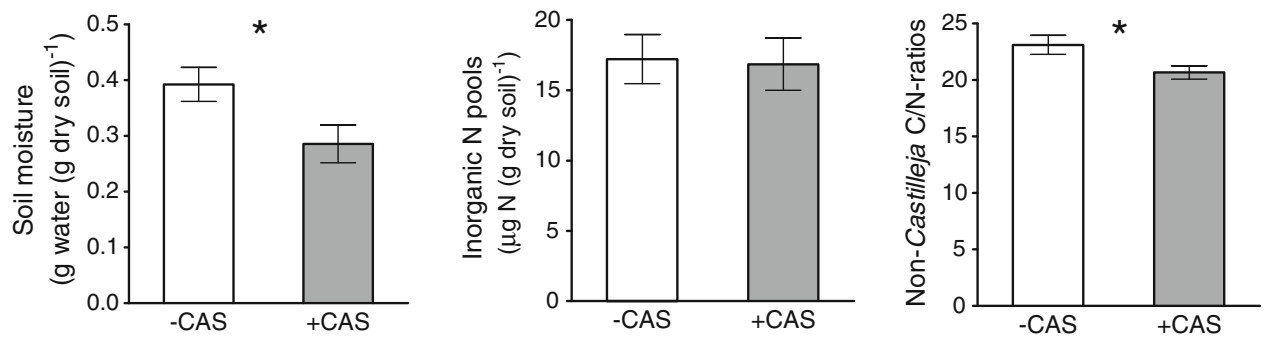

Fig. 3 Resource measurements (mean $\pm \mathrm{SE}$ ) in $+C A S$ and $-\mathrm{CAS}$. Soil moisture (a) was significantly lower in association with Castilleja as compared to the surrounding tundra. There was no difference in b extractable inorganic $\mathrm{N}$ between +CAS plots and -CAS plots.
However, foliar C:N (c) was lower in the non-Castilleja portion of the + CAS community indicating more available inorganic N. For abbreviations, see Fig. 2 . $* P<0.05 ; n=15$ for each treatment
Fig. 4 Direct litter effects. Mean $( \pm$ SE) values for a $\%$ mass remaining and $\mathbf{b} \% \mathrm{~N}$ loss for each of the five species used and the community mix which was composed of equal part of all species except Castilleja. ART Artemisia scopulorum, CAR Carex scopulorum, CAS Castilleja. occidentalis, GEU Geum rossii, KOB Kobresia myosuroides, MIX community $\operatorname{mix}$

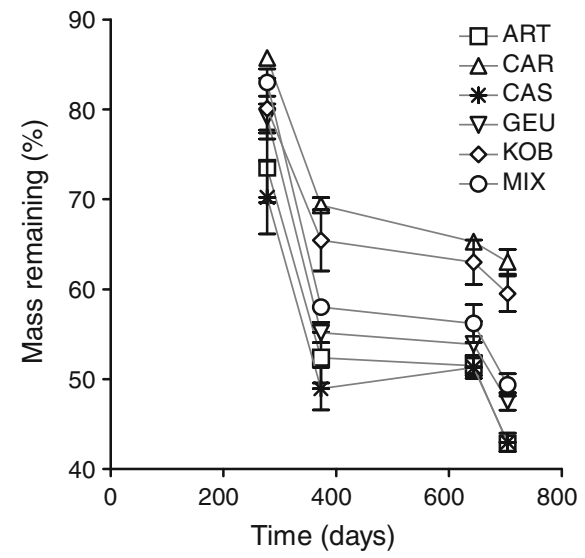

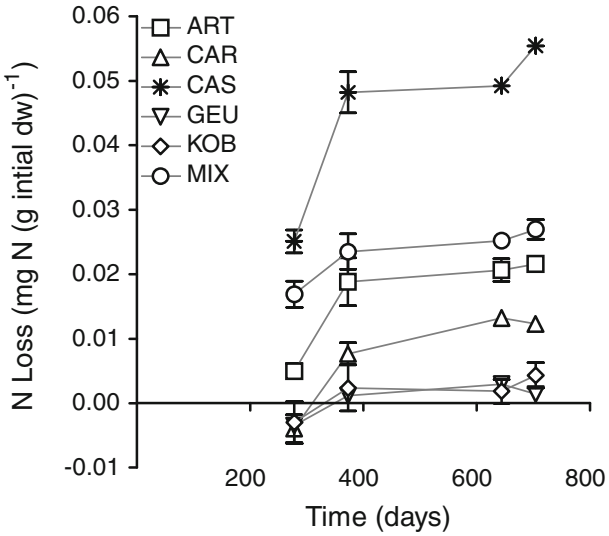

Table 1 Direct and litter mixing effects on mass loss

\begin{tabular}{|c|c|c|c|c|c|}
\hline \multirow[t]{2}{*}{ Species } & \multicolumn{2}{|l|}{ Observed } & \multicolumn{2}{|l|}{ Expected } & \multirow[t]{2}{*}{$P$ value } \\
\hline & $k$ (mean) & $k(\mathrm{SE})$ & $k$ (mean) & $k(\mathrm{SE})$ & \\
\hline Artemisia & $0.034 \mathrm{a}$ & 0.0010 & & & \\
\hline Carex & $0.020 \mathrm{e}$ & 0.0007 & & & \\
\hline Castilleja & $0.033 \mathrm{ab}$ & 0.0011 & & & \\
\hline Geum & $0.032 \mathrm{ab}$ & 0.0014 & & & \\
\hline Kobresia & $0.022 \mathrm{e}$ & 0.0010 & & & \\
\hline Community mix & $0.027 \mathrm{~cd}$ & 0.0004 & & & \\
\hline Artemisia + Castilleja & $0.034 \mathrm{a}$ & 0.0017 & 0.034 & 0.0007 & 0.89 \\
\hline Carex + Castilleja & $0.029 \mathrm{~cd}$ & 0.0014 & 0.024 & 0.0015 & 0.06 \\
\hline $\begin{array}{l}\text { Community mix }+ \\
\text { Castilleja }\end{array}$ & $0.030 \mathrm{bc}$ & 0.0013 & 0.026 & 0.0010 & $\mathbf{0 . 0 3}$ \\
\hline Geum + Castilleja & $0.030 \mathrm{bc}$ & 0.0019 & 0.028 & 0.0022 & 0.56 \\
\hline Kobresia + Castilleja & $0.027 \mathrm{~cd}$ & 0.0010 & 0.028 & 0.0004 & 0.48 \\
\hline
\end{tabular}

Mean $( \pm$ SE) and $P$ values for the annual decay constant $(k)$ for each species, and both expected and observed values for mixtures with Castilleja. Observed values for $k$ were calculated using the single negative exponential model. The expected values for a mixture were calculated as $\left[\left(\right.\right.$ Species $A_{\text {alone }}+$ Species $\left.\left.B_{\text {alone }}\right) / 2\right]$ for a two species mixture. Different letters represent significant differences $(P \leq 0.05)$ in observed decay

Bold values indicate significant or marginally significant $P$ values

hemiparasites directly boost non-host productivity, our work suggests that hemiparasites can potentially boost total community productivity (both host and non-host).
In more nutrient-rich grassland systems, shorter lived hemiparasites have been found to reduce productivity (Marvier 1998; Bardgett et al. 2006) and increase diversity (Ameloot et al. 2005; Bardgett et al. 2006) indicating the importance of parasitism. For instance, Rhinanthus, the most studied genus of hemiparasites, are annual species whose abundance is strongly influenced by stochastic climate fluctuations (Ameloot et al. 2006). Due to the large changes in Rhinanthus abundance because of climate fluctuations, there is likely little long-term litter accumulation in natural field settings (Ameloot et al. 2006), and thus less possibility for litter effects to develop. It is important to note however, that Ameloot et al. (2008) found greater soil $\mathrm{N}$ pools in grasslands parasitized by Rhinanthus minor and a significant decrease in host biomass. However, these higher $\mathrm{N}$ pools would likely not compensate for the effects of parasitism as this study was conducted in Western European grasslands, which are highly impacted by $\mathrm{N}$ deposition (Dentener et al. 2006) and the study site was likely not $\mathrm{N}$ limited as a result of the $\mathrm{N}$ deposition (Ameloot et al. 2008).

Productivity in the alpine tundra where we conducted this study is known to be $\mathrm{N}$ limited (Bowman et al. 1993), and alpine species at our research site compete for $\mathrm{N}$ (Song et al. 2006; Miller et al. 2007; Ashton et al. 2008). Castilleja likely reduces competition for $\mathrm{N}$ in the dry meadow by increasing the amount of available $\mathrm{N}$ via litter 
Fig. 5 Litter mixing effects on $\mathrm{N}$ loss. Mean $( \pm \mathrm{SE})$ values for percent $\mathrm{N}$ loss. a-e Observed $\% \mathrm{~N}$ loss (white symbols) of mixtures of each of the four species and the community mix with Castilleja compared to expected \% $\mathrm{N}$ loss (black symbols). Observed $\mathrm{N}$ loss was calculated as the difference between initial litter $\mathrm{N}$ (time zero; litter dry weight $\times \mathrm{N}$ concentration) and litter $\mathrm{N}$ for each time point (times $1-4)$. The expected values for a mixture were calculated as [(Species $\mathrm{A}_{\text {alone }}+$ Species $\mathrm{B}_{\text {alone }} / 2$ ] for a two species mixture. For abbreviations, see Fig. 4. $* P<0.05$ between expected and observed values; $n=4$ for each treatments at each time point

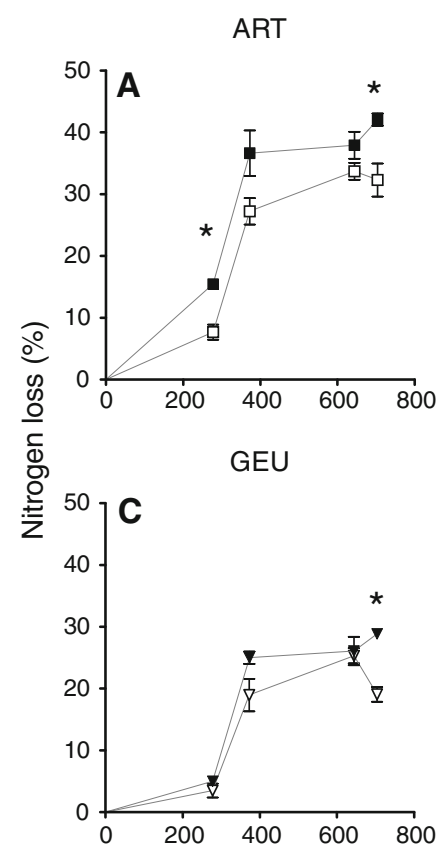

CAR

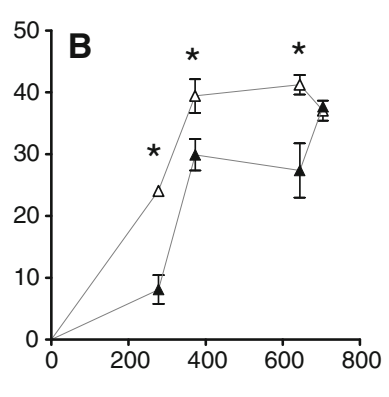

$\mathrm{KOB}$

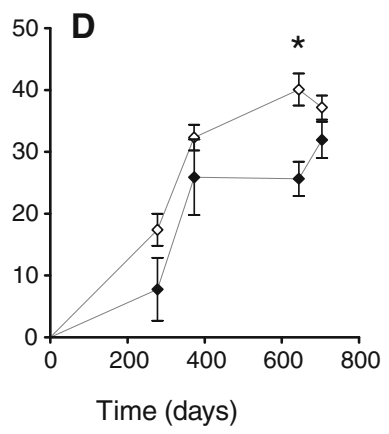

MIX

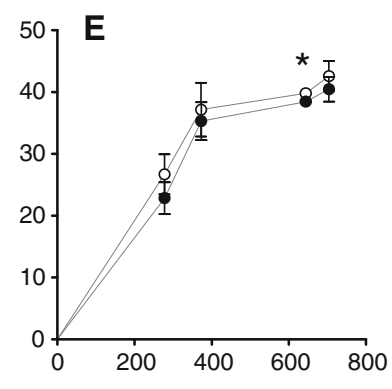

effects. While we did not find an increase in inorganic $\mathrm{N}$ pools, we did find that litter $\mathrm{N}$ loss rates and the foliar $\mathrm{N}$ concentrations of co-occurring species associated with Castilleja were higher. Similarly, Quested et al. (2003b) found that seedlings grown with litter from hemiparasitic Bartsia had higher foliar $\mathrm{N}$ than seedlings grown with non-hemiparasitic litter. Future research should examine $\mathrm{N}$ cycling in more detail as soil cores are point measurements that miss $\mathrm{N}$ dynamics over time. Castilleja likely speeds up $\mathrm{N}$ cycling, increasing biomass production and $\mathrm{N}$ content of co-occurring species through litter effects. In some of the only other direct work on hemiparasites and decomposition, Quested et al. $(2002,2005)$ found that litter of the hemiparasite Bartsia both decomposed more rapidly than co-occurring species and accelerated the decomposition of co-occurring species. We found similar rapid decomposition in Castilleja, particularly in terms of greater $\mathrm{N}$ loss. These results suggest that the rapid decomposition of Castilleja litter is one direct mechanism of compensation for the negative effects of parasitism by a hemiparasite. We also found that Castilleja litter accelerated the decomposition of co-occurring species, again particularly on $\mathrm{N}$ loss, and that these effects were dependant on the species mixed with Castilleja. These mixing effects suggest a second mechanism of compensation for the negative effects of parasitism by a hemiparasite. Our results suggest that with these direct and mixing effects Castilleja can release more available $\mathrm{N}$ to the system, thus speeding the typically slow $\mathrm{N}$ cycle in the alpine tundra and boosting productivity.
Our results indicate that the direct effects of hemiparasites may be more important and widespread than the litter mixing effects, which may be more constrained by the community in which the hemiparasite is found. While we found little impact of hemiparasite litter on mass loss, but substantial impacts on N loss, Quested et al. (2002, 2005) found that the hemiparasite Bartsia accelerated mass loss and $\mathrm{CO}_{2}$ efflux, but not $\mathrm{N}$ loss in litter mixtures. Additionally, Quested et al. (2005) did not find litter effects in field litter incubations. These differences may be due to the species chosen. Quested et al. $(2002,2005)$ used shrubs whose litter contains high levels of lignin, a compound associated with slow decomposition (Melillo et al. 1982). These high lignin levels may explain why Quested et al. (2002) found slower than expected $\mathrm{N}$ loss. Where we did find significant $\mathrm{N}$ loss, it was with graminoids, species that typically have lower levels of lignin (Hobbie 1996). Similar to the typically slowly decomposing shrubs, both Artemisia and Geum contain compounds associated with slow decomposition. Geum produces phenolics (Steltzer and Bowman 1998) and Artemisia produces terpenes (Gibbs 1974), both of which are associated with slow N cycling (White 1994; Kraus et al. 2003; Bowman et al. 2004; Nierop et al. 2006; Orwin et al. 2006).

While this work did not isolate the effects of parasitism directly, several lines of evidence suggest that parasitism was occurring in the study. We found that Geum was in lower abundance with Castilleja. This lower abundance of Geum might have been a weak signal of Castilleja parasitism. Additionally, we assume Castilleja is acting as a parasite 
because the foliar $\mathrm{N}$ concentrations of Castilleja were higher than in the surrounding community. Work on facultative hemiparasites has shown that unattached hemiparasites tend to have similar or lower foliar $\mathrm{N}$ concentrations than their potential host species (Seel and Press 1993). Hemiparasite that are attached and parasitizing tend to have higher foliar $\mathrm{N}$ concentrations due to their low nutrient use efficiency (Matthies 1995; Matthies 1997; Marvier 1998; Shen et al. 2006).

Lastly, it has been proposed that hemiparasites may reduce soil moisture as a result of one of the mechanisms of parasitism (Sala et al. 2001). Hemiparasites, once they attach to a host plant, draw up nutrients and water from the host xylem by maintaining high transpiration rates (Stewart and Press 1990; Ehleringer and Marshall 1995). These high transpiration rates and the associated increased water uptake by the host plants could be responsible for the reduction in soil moisture we found in association with Castilleja. While the greater biomass associated with Castilleja could also decrease soil moisture regardless of transpiration rates, we found no relationship between biomass and soil moisture. While our results are only correlative, this mechanism by which hemiparasites can reduce soil moisture and potentially affect ecosystem functioning should be explored further.

Several studies have now assessed the impacts of hemiparasites on community structure (Davies et al. 1997; Callaway and Pennings 1998; Marvier 1998; Hedberg et al. 2005; Westbury and Dunnett 2007) or ecosystem function (Quested et al. 2002; Quested et al. 2003b; Quested et al. 2005; Ameloot et al. 2008). However, effects have been variable and few studies have jointly assessed the impacts of a hemiparasite on both community structure and ecosystem function. We speculate that the net effect of hemiparasites on aboveground productivity and diversity should depend on whether hemiparasites more strongly reduce host growth (parasitism) or enhance nutrient cycling (litter effects). In situations where there are stronger effects of parasitism, we propose that hemiparasites should increase diversity of the non-host community and decrease host and total community productivity. In contrast, if positive litter effects on nutrient supply compensate for the reduction in host biomass, we would expect minimal to no change in diversity, minor effects on host biomass, and an increase in the total biomass of the community. While short-lived hemiparasites often have stronger impacts via parasitism (Ameloot et al. 2005; Bardgett et al. 2006), our results and those of Quested et al. (Quested et al. 2002, 2003b, 2005) and March and Watson (2007) suggest that long-lived hemiparasites have stronger impacts via litter effects. It is important to note that our work is only associative; rather than causing these patterns, Castilleja may "prefer" or survive better in patches with higher host biomass and higher
$\mathrm{N}$ availability. Future work with removal experiments and work comparing the effects of short- and long-lived hemiparasites will provide a direct test of these ideas. As hemiparasites are ubiquitous and play strong roles in both community structure and ecosystem function, understanding the relative importance of these two pathways is crucial to understanding how hemiparasites impact communities.

Acknowledgments This work was funded by the Andrew W. Mellon Foundation, with support from the Niwot Ridge Long-Term Ecological Research Program (NSF 0423662). We thank D. Tank for sharing his expertise on Castilleja, C. Seibold for analytical support, and J. Murgle, L. Larios, M. Khosh and R. Massoumi for help in the field and laboratory. We also thank W. Bowman, I. Ashton, and the anonymous reviewers for helpful discussions and comments on early drafts of this manuscript. This study complies with the current laws of the country in which it was preformed.

Open Access This article is distributed under the terms of the Creative Commons Attribution Noncommercial License which permits any noncommercial use, distribution, and reproduction in any medium, provided the original author(s) and source are credited.

\section{References}

Ameloot E, Verheyen K, Hermy M (2005) Meta-analysis of standing crop reduction by Rhinanthus spp. and its effect on vegetation structure. Folia Geobot 40:289-310

Ameloot E, Verheyen K, Bakker JP, De Vries Y, Hermy M (2006) Long-term dynamics of the hemiparasite Rhinanthus angustifolius and its relationship with vegetation structure. J Veg Sci 17:637-646

Ameloot E, Verlinden G, Boeckx P, Verheyen K, Hermy M (2008) Impact of hemiparasitic Rhinanthus angustifolius and R. minor on nitrogen availability in grasslands. Plant Soil 311:255-268

Ashton IW, Miller AE, Bowman WD, Suding KN (2008) Nitrogen preferences and plant-soil feedbacks as influenced by neighbors in the alpine tundra. Oecologia 156:625-636

Bardgett RD et al (2006) Parasitic plants indirectly regulate belowground properties in grassland ecosystems. Nature 439:969-972

Bowman WD, Theodose TA, Schardt JC, Conant RT (1993) Constraints of nutrient availability on primary production in 2 alpine tundra communities. Ecology 74:2085-2097

Bowman WD, Steltzer H, Rosenstiel TN, Cleveland CC, Meier CL (2004) Litter effects of two co-occurring alpine species on plant growth, microbial activity and immobilization of nitrogen. Oikos 104:336-344

Callaway RM, Pennings SC (1998) Impact of a parasitic plant on the zonation of two salt marsh perennials. Oecologia 114:100-105

Chuang TI, Heckard LR (1991) Generic realignment and synopsis of subtribe Castillejinae (Scrophulariaceae-Tribe Pediculareae). Syst Bot 16:644-666

Davies DM, Graves JD, Elias CO, Williams PJ (1997) The impact of Rhinanthus spp. on sward productivity and composition: implications for the restoration of species-rich grasslands. Biol Conserv 82:87-93

Dentener F et al (2006) Nitrogen and sulfur deposition on regional and global scales: a multimodel evaluation. Global Biogeochem Cycles 20, article no. GB4003

Ehleringer JR, Marshall JD (1995) Water Relations. In: Press MC, Graves JD (eds) Parasitic Plants. Chapman and Hall, London, pp 1-13 
Gibbs RD (1974) Chemotaxonomy of flowering plants. McGill-Queen's University Press, Montreal

Gibson CC, Watkinson AR (1992) The role of the hemiparasitic annual Rhinanthus minor in determining grassland community structure. Oecologia 89:62-68

Greenland D, Losleben M (2001) Climate. In: Bowman WD, Seastedt TR (eds) Structure and function of an alpine ecosystem. Oxford University Press, New York, pp 15-31

Harmon ME, Naelhoffer KJ, Blair JM (1999) Measuring decomposition, nutrient turnover, and stores in plant litter. In: Robertson GP, Coleman DC, Bledsoe CS, Sollins P (eds) Standard soil methods for long-term ecological research. Oxford University Press, New York, pp 202-240

Hedberg AM, Borowicz VA, Armstrong JE (2005) Interactions between a hemiparasitic plant, Pedicularis canadensis L. (Orobanchaceae), and members of a tallgrass prairie community. J Torrey Bot Soc 132:401-410

Hobbie SE (1996) Temperature and plant species control over litter decomposition in Alaskan tundra. Ecol Monogr 66:503-522

Kraus TEC, Yu Z, Preston CM, Dahlgren RA, Zasoski RJ (2003) Linking chemical reactivity and protein precipitation to structural characteristics of foliar tannins. J Chem Ecol 29:703-730

March WA, Watson DM (2007) Parasites boost productivity: effects of mistletoe on litterfall dynamics in a temperate Australian forest. Oecologia 154:339-347

Marvier MA (1998) Parasite impacts on host communities: plant parasitism in a California coastal prairie. Ecology 79:2616-2623

Matthies D (1995) Parasitic and competitive interactions between the hemiparasites Rhinanthus-Serotinus and Odontites-Rubra and their host medicago-sativa. J Ecol 83:245-251

Matthies D (1997) Parasite-host interactions in Castilleja and Orthocarpus. Can J Bot Rev 75:1252-1260

Melillo JM, Aber JD, Muratore JF (1982) Nitrogen and lignin control of hardwood leaf litter decomposition dynamics. Ecology 63:621-626

Miller AE, Bowman WD, Suding KN (2007) Plant uptake of inorganic and organic nitrogen: neighbor identity matters. Ecology $88: 1832-1840$

Nierop KGJ, Preston CM, Verstraten JM (2006) Linking the B ring hydroxylation pattern of condensed tannins to $\mathrm{C}, \mathrm{N}$ and $\mathrm{P}$ mineralization. A case study using four tannins. Soil Biol Biochem 38:2794-2802

Orwin KH, Wardle DA, Greenfield LG (2006) Ecological consequences of carbon substrate identity and diversity in a laboratory study. Ecology 87:580-593

Pennings SC, Callaway RM (1996) Impact of a parasitic plant on the structure and dynamics of salt marsh vegetation. Ecology 77:1410-1419

Pennings SC, Callaway RM (2002) Parasitic plants: parallels and contrasts with herbivores. Oecologia 131:479-489

Phoenix GK, Press MC (2005) Linking physiological traits to impacts on community structure and function: the role of root hemiparasitic Orobanchaceae (ex-Scrophulariaceae). J Ecol 93:67-78
Press MC (1998) Dracula or Robin Hood? A functional role for root hemiparasites in nutrient poor ecosystems. Oikos 82:609-611

Press MC, Phoenix GK (2005) Impacts of parasitic plants on natural communities. New Phytol 166:737-751

Press MC, Scholes JD, Watling JR (1999) Parasitic plants: physiological and ecological interactions with their hosts. In: Press MC, Scholes JD, Barker MG (eds) Physiological plant ecology. Blackwell Science, Oxford, pp 175-197

Quested HM (2008) Parasitic plants-impacts on nutrient cycling. Plant Soil 311:269-272

Quested HM, Press MC, Callaghan TV, Cornelissen JHC (2002) The hemiparasitic angiosperm Bartsia alpina has the potential to accelerate decomposition in sub-arctic communities. Oecologia 130:88-95

Quested HM et al (2003a) Decomposition of sub-arctic plants with differing nitrogen economies: a functional role for hemiparasites. Ecology 84:3209-3221

Quested HM, Press MC, Callaghan TV (2003b) Litter of the hemiparasite Bartsia alpina enhances plant growth: evidence for a functional role in nutrient cycling. Oecologia 135:606-614

Quested HM, Callaghan TV, Cornelissen JHC, Press MC (2005) The impact of hemiparasitic plant litter on decomposition: direct, seasonal and litter mixing effects. J Ecol 93:87-98

Sala A, Carey EV, Callaway RM (2001) Dwarf mistletoe affects whole-tree water relations of Douglas fir and western larch primarily through changes in leaf to sapwood ratios. Oecologia 126:42-52

Seel WE, Press MC (1993) Influence of the host on 3 Sub-Arctic annual facultative root hemiparasites. 1. Growth, mineral accumulation and aboveground dry-matter partitioning. New Phytol 125:131-138

Shen $\mathrm{H}$ et al (2006) Progress in parasitic plant biology: host selection and nutrient transfer. Plant Biol 8:175-185

Siegel RS, Hauck RD, Kurtz LT (1982) Determination of (N2)-N-30 and application to measurement of $\mathrm{N}-2$ evolution during denitrification. Soil Sci Soc Am J 46:68-74

Song MH, Tian YQ, Xu XL, Hu QW, Hua OY (2006) Interactions between root and shoot competition among four plant species in an alpine meadow on the Tibetan Plateau. Acta Oecol Int J Ecol 29:214-220

Steltzer H, Bowman WD (1998) Differential influence of plant species on soil nitrogen transformations within moist meadow alpine tundra. Ecosystems 1:464-474

Stewart GR, Press MC (1990) The physiology and biochemistry of parasitic angiosperms. Annu Rev Plant Physiol Plant Mol Biol 41:127-151

Weber WA, Wittmann RC (2001) Colorado flora: eastern slope. University Press of Colorado, Boulder

Westbury DB, Dunnett NP (2007) The impact of Rhinanthus minor in newly established meadows on a productive site. Appl Veg Sci 10:121-129

White CS (1994) Monoterpenes-their effects on ecosystem nutrient cycling. J Chem Ecol 20:1381-1406 